\title{
Accessory Muscles: A Cause of Nerve Compression in the Distal Forearm. Case Report and Literature Review
}

\author{
Músculos Accesorios: una Causa de Compresión Nerviosa en el Antebrazo Distal. \\ Reporte de Casos y Revisión de la Literatura
}

Javier Román Veas*; Pedro Ruiz Conrads*** \& Jefferson Braga Silva****

ROMÁN-VEAS, J.; RUIZ-CONRADS, P. \& BRAGA-SILVA, J. Accessory muscles: A cause of nerve compression in the distal forearm. Case report and literature review. Int. J. Morphol., 34(1):97-101, 2016.

SUMMARY: Nerve compression by anomalous muscles located at the wrist and distal forearm is an infrequent condition. Accessory muscles may compress underlying structures in the Carpal Tunnel region or ulnar canal, producing pain and paresthesia. Two cases of ulnar and median nerve compression, caused by prominent accessory muscles at the distal forearm, are described. Literature review is presented.

KEY WORDS: Muscles; Nerve Compression Syndromes; Anatomic Variation.

\section{INTRODUCTION}

Nerve compression by anomalous muscles located at the wrist and distal forearm is an infrequent condition, few reports exist in literature (Zeiss \& Guilliam-Haidet, 1996; Ruocco et al., 1998; Harvie et al., 2004). Accessory muscles may compress underlying structures in the carpal tunnel region or ulnar canal, causing pain and paresthesias (Morrison, 1916; Ryu \& Watson, 1987; Sañudo et al., 1993; Server et al., 1995; Sanchez Lorenzo et al., 1996; Depuydt et al., 1998; Santoro et al., 2000; Schuurman \& van Gils, 2000; Soldado-Carrera et al., 2000; Bozkurt et al., 2005; Jones, 2006, Acikel et al., 2007; Ogun et al., 2007). Two cases of ulnar and median nerve compression at the distal forearm, caused by prominent accessory muscles at the distal forearm, are reported.

\section{CASE REPORT}

Case 1. A twenty-one-year-old female patient, right handed, complained of numbness and paresthesia over distal ulnar nerve territory on her right hand for a period of six months, prior to care seeking at an outpatient facility. She denied traumatic events or any other health problems before the beginning of her symptoms. Physical examination revealed tenderness over her ulnar side of the wrist, but there was no evidence of tumor or mass when examined. She had negative Tinel sign over her forearm and wrist. No atrophy or weakness of the intrinsic muscles was present on her right hand. Low-resolution ultrasound testing reported nonspecific synovitis. Nerve conduit study showed no abnormality.

After a 3 month period of observation time and pain management, patient showed no improvement and surgical exploration of the ulnar side of the wrist and forearm was advised.

During surgical exploration, a muscle, with normal appearance crossed over the ulnar neurovascular bundle, at distal forearm, proximal to the wrist (Figs. 1-2). Surgical exploration was expanded both proximally and distally in order to achieve full view of the origin and insertion sites. Compromised underlying structures were released. Ulnar canal exploration was also performed.

\footnotetext{
Médico Traumatólogo, Profesor Asistente, Departamento de Ortopedia y Traumatología-Departamento de Anatomía, Pontificia Universidad Católica de Chile, Santiago, Chile.

** Médico. Residente del Departamento de Ortopedia y Traumatología, Pontificia Universidad Católica de Chile, Santiago, Chile.

**** Médico Director Facultad de Medicina; Pontificia Universidad Católica de Rio Grande del Sul (PUCRS), Porto Alegre, Brasil.
} 


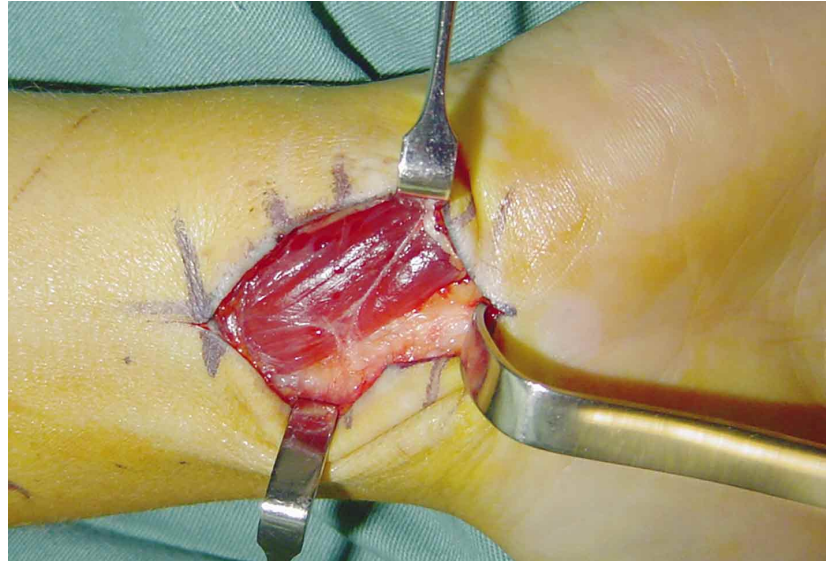

Fig. 1. Left wrist, fingers to the right: Accessory abductor digiti minimi just under skin at the ulnar side of left volar wrist.

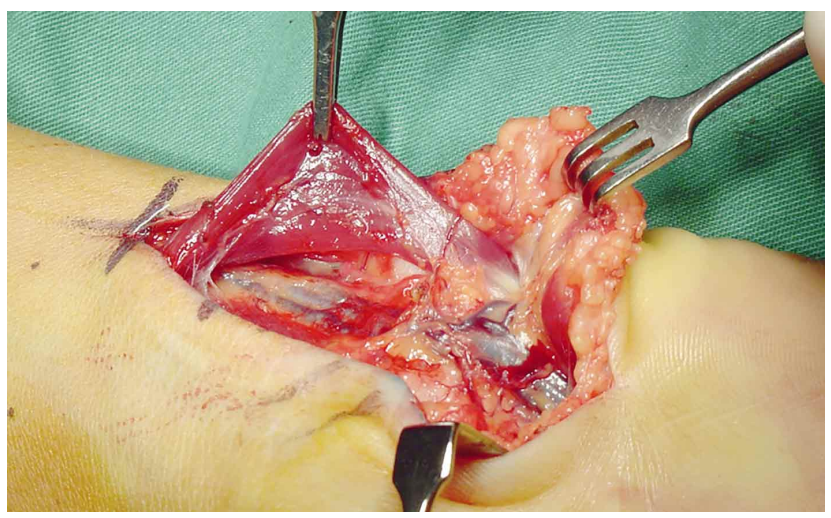

Fig. 2. Left wrist, fingers to the right: Accessory abductor digiti minimi pushed up by forceps reveling ulnar artery and nerve bundle underneath.

The anomalous muscle originated from the anteromedial aspect of the palmaris longus tendon about $3.5 \mathrm{~cm}$ proximal to the wrist crease and inserted over the fascia of the abductor digiti minimi muscle (Fig. 3). The muscle was located over flexor carpi ulnaris muscle, ulnar side of flexor digitorum superficialis tendons and crossed over the proximal third of ulnar canal, in close contact with the ulnar nerve and vessels.

Origin site, meshed with the abductor digiti minimi muscle. Muscle dimensions in situ were, $6.0 \mathrm{~cm}$ long, 2.0 $\mathrm{cm}$ wide and $1.0 \mathrm{~cm}$ thick. No other abnormalities were observed. The muscle was excised in order to decompress ulnar canal.

After surgery, symptomatic relief was fully accomplished. Histopathologic report described normal muscle tissue.

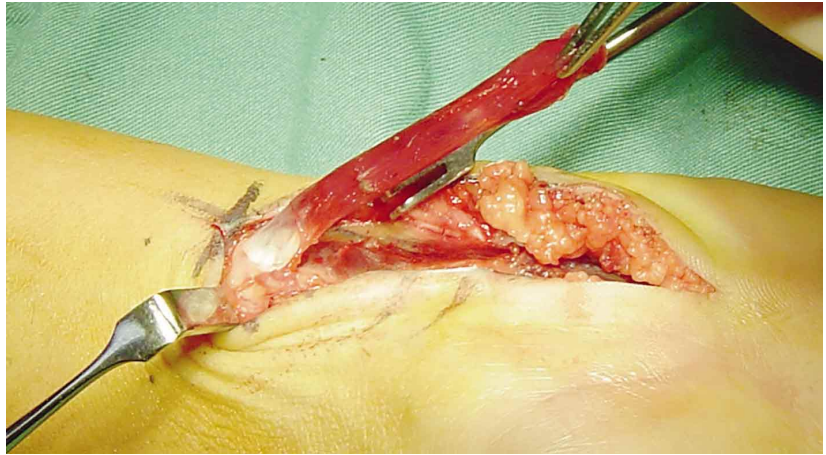

Fig. 3. Left wrist, fingers to the right: Surgical resection showing the anomalous muscle originated from the antero-medial aspect of the palmaris longus tendon.

Case 2. A 27-year-old male patient, right handed, engineer, complained of numbness over his right hand and referred sore pain at his right distal forearm. Symptoms worsened after weight lifting and computer typing. Patient received anti-inflammatory drugs, physical therapy, wrist splinting, and medical rest over a one-month period. No symptomatic improvement was obtained. Low resolution ultrasound testing reported flexor tenosynovitis. No other abnormalities were informed.

Physical assessment showed a bulky mass over the ulnar side of the distal forearm (Fig. 4), which increased in volume during wrist flexion and ulnar deviation against resistance. The anomalous enlargement was also evident when the fifth finger was tested in abduction against resistance. Hypoesthesia was found to be present at the volar ulnar side of the right hand, with normal sensibility over the dorsal-ulnar aspect of the hand. Froment's sign was present.

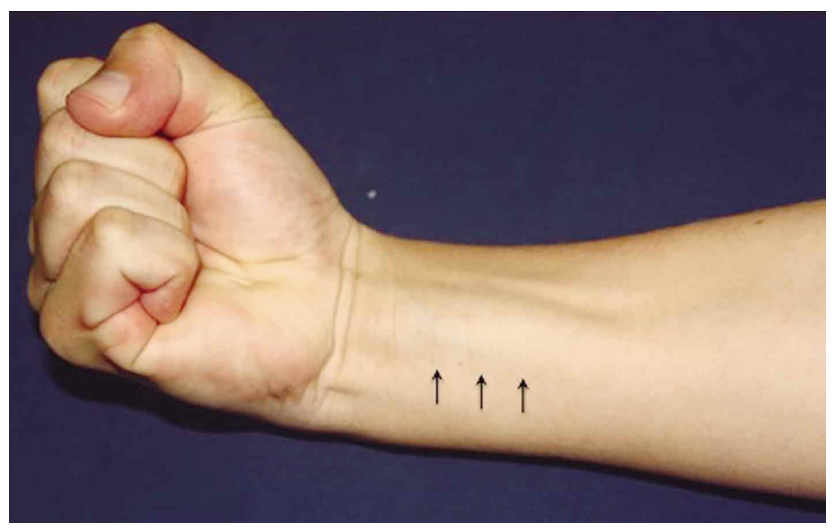

Fig. 4. Bulky mass over the middle-ulnar side of the distal right forearm (arrows).

A second ultrasound study, with a high-resolution technique, and a well-trained muscle skeletal radiologist, 
was performed. Reverse palmaris longus and accessory abductor digiti minimi muscles were reported. Persistent median artery was also found. No additional testing was applied.

Surgical exploration was indicated in order to release nerve compression. A flat, wide muscle over the median and ulnar nerve appeared present immediately beneath skin incision (Fig. 5).

Three insertion sites were present. The most radial and superficial insertion, fused with the palmar aponeurosis, as a normal palmaris longus tendon. Underneath the recently described, a second and wider insertion, meshed with the flexor retinaculum, which was found to be the main distal insertion site of this accessory muscle. A third, muscular and most ulnar insertion crossed over the ulnar neurovascular bundle and joined the normal abductor digiti minimi muscle (Fig. 6).

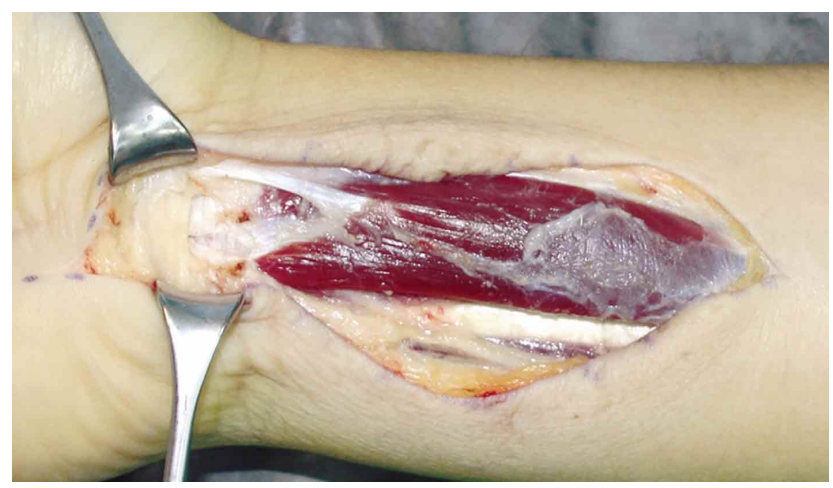

Fig. 5. A flat, wide muscle over the median and ulnar nerve appeared present immediately beneath skin incision.

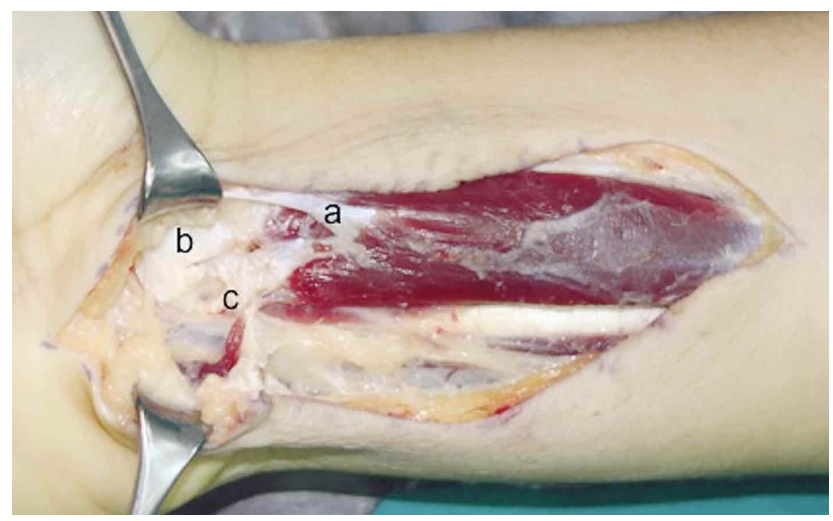

Fig. 6. Three insertion sites were present. The most radial and superficial insertion, fused with the palmar aponeurosis, as a normal palmaris longus tendon (a). Underneath a second and wider insertion, meshed with the flexor retinaculum, which was found to be the main insertion site of this accessory muscle (b). A third, muscular and most ulnar insertion crossed over the ulnar neurovascular bundle and joined the normal abductor digiti minimi muscle (c).

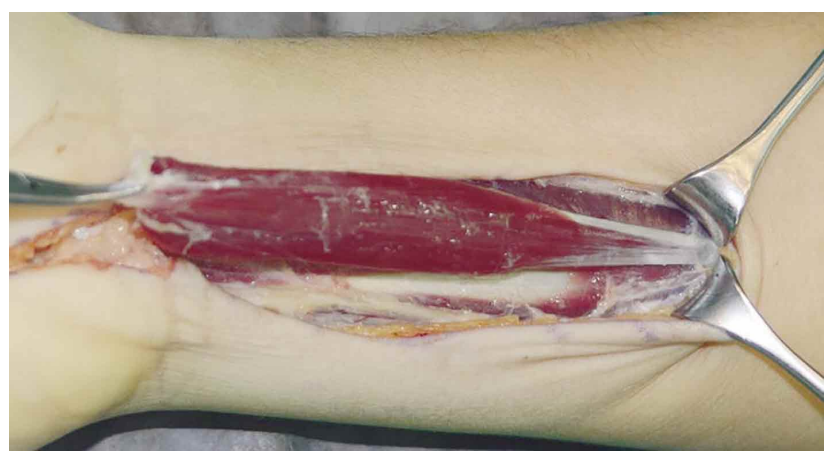

Fig. 7. Proximal insertion site was found at the proximal antebrachial fascia.

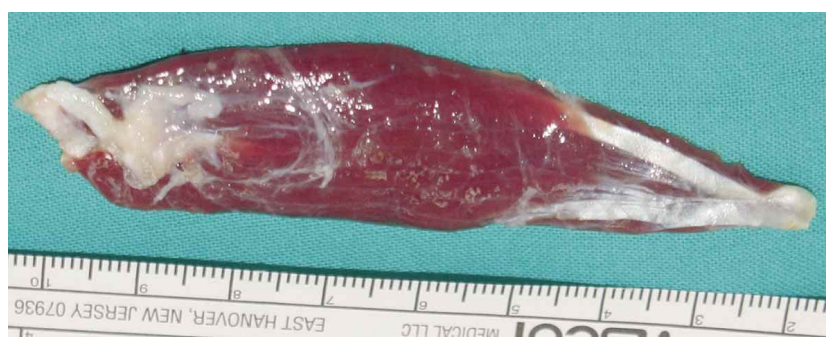

Fig. 8. Accessory muscle with normal tissue appearance.

Origin site was located at the proximal antebrachial fascia (Fig. 7). Clinical appearance was a normal muscle and pathologist informed normal muscle tissue (Fig. 8).

After excision, full symptomatic recovery was achieved.

\section{DISCUSSION}

The palmaris longus muscle is probably one of the most variable muscles located in the upper limb. Alike the palmaris, the abductor digiti minimi muscle is considered to be the most variable of all the hypothenar muscles, being its accessory muscle belly presentation the most frequent of them all (Soldado-Carrera et al.).

The origins of the accessory muscle bellies are mostly found in the lower third of the superficial compartment of the anterior forearm. In general, there is a single origin site, which is most frequently found in the antebrachial fascia. It may also originate from the palmaris longus tendon. Double origin, has also been described, coming from the palmaris longus tendon and superficial antebrachial fascia or, from the flexor carpi ulnaris tendon and deep antebrachial fascia. The origin of the accessory muscles in this report was found at the palmaris longus tendon in case 1 and at the antebrachial fascia in case 2 . 
ROMÁN-VEAS, J.; RUIZ-CONRADS, P. \& BRAGA-SILVA, J. Accessory muscles: A cause of nerve compression in the distal forearm. Case report and literature review. Int. J. Morphol., 34(1):97-101, 2016.

Different kinds of insertions of these accessory formations have been reported. In the cases presented above, insertion was single, and blended with the normal digiti minimi muscle belly in case 1 . In the second case, a triple insertion was observed, fusing with palmar aponeurosis, flexor retinaculum and abductor digiti minimi muscle, from radial to ulnar. Three headed reverse palmaris longus muscles, with similar distal insertions have been reported previously in literature (Yildiz et al., 2000; Acikel et al.; Natsis et al., 2007).

Anatomical reports describe that, muscle variations at the distal forearm are frequent, and are mostly reported by radiologists during MRI or ultrasound imaging studies (Zeiss \& Jakab, 1995; Zeiss \& Guilliam-Haidet; Ruocco et al.; Schuurman \& van Gils 2000; Yildiz et al.; Bencteux et al., 2001; Harvie et al.). Accessory muscles located at the palmar aspect of the distal forearm are highly variable in their morphology. A prevalence study, in non symptomatic volunteers, using ultrasound of distal forearm and wrist, revealed up to $47 \%$ of patients with evidence of anomalous muscles, all of which, were variants of abductor digiti minimi muscle. A male over female prevalence was observed, and in $50 \%$ of the cases, the condition was found to be bilateral. Muscle thickness did not vary with hand dominance or manual employment (Harvie et al.).

Cihák (1972) described the embryological development of forearm and hand muscles. The superficial muscle layer differentiates into three blastemas: radial, middle and ulnar blastemas. These blastemas give rise to the abductor pollicis brevis, flexor digitorum superficialis and abductor digiti minimi muscles, respectively. The flexor digitorum superficialis muscle as the other blastemas, find their origin at the carpal region. Unlike the other, the flexor digitorum superficialis blastema migrates proximately, while the abductor digiti minimi and abductor pollicis brevis muscles remain in the same carpal region. Soldado-Carrera describes muscle variations in the forearm by a persistent group of undifferentiated mesenchymal cells. These cells, probably fail in their usual apoptosis process, resulting in supernumerary muscles and variation of the anatomic presentation of distal forearm muscles (Soldado-Carrera et al.).

Despite these anatomical considerations, clinical reports of nerve compression at the wrist by accessory muscles are scarce. Evidence presented by clinical and anatomical studies is discordant.

In conclusion, the presence of accessory abductor digiti minimi, among other variant anatomical presentations, though appears to be a frequent finding in imaging studies, is scarcely reported as a cause of nerve compression at the distal forearm. Given in consideration the large proportion of muscle variations present in general, non-symptomatic population, caregivers should accomplish to asses muscle variations as a possible cause of nerve compression, in order to improve patient management.

Both patients presented in this paper, had discomfort related to effort and postural changes. During wrist extension, accessory or aberrant muscle bellies might stretch out neurovascular structures in the surroundings of carpal tunnel or ulnar canal, causing compression symptoms.

ROMÁN-VEAS, J.; RUIZ-CONRADS, P. \& BRAGA-SILVA, J. Músculos accesorios: una causa de compresión nerviosas en el antebrazo distal. Reporte de casos y revisión de la literatura. Int. J. Morphol., 34(1):97-101, 2016.

RESUMEN: La compresión nerviosa causada por vientres musculares anómalos localizados en la muñeca y en el tercio distal del antebrazo es una condición poco frecuente. Músculos accesorios pueden comprimir estructuras subyacentes en la región del túnel del carpo o en el canal de ulnar, produciendo dolor y parestesia. Se presentan dos casos de compresión de los nervios ulnar y mediano en el tercio distal del antebrazo, causados por vientres musculares prominentes de músculos accesorios del antebrazo. Se presenta una revisión de la literatura.

PALABRAS CLAVE: Músculos del antebrazo; Síndrome de compresión nerviosa; Variación anatómica.

\section{REFERENCES}

Acikel, C.; Ulkur, E.; Karagoz, H. \& Celikoz, B. Effort-related compression of median and ulnar nerves as a result of reversed three-headed and hypertrophied palmaris longus muscle with extension of Guyon's canal. Scand. J. Plast. Reconstr. Surg. Hand Surg., 41(1):45-7, 2007.

Bencteux, P.; Simonet, J.; el Ayoubi, L.; Renard, M.; Attignon, I, Dacher, J. N. \& Thiebot, J. Symptomatic palmaris longus muscle variation with MRI and surgical correlation: report of a single case. Surg. Radiol. Anat., 23(4):273-5, 2001.

Bozkurt, M. C.; Tagil, S. M.; Ozçakar, L.; Ersoy, M. \& Tekdemir, I. Anatomical variations as potential risk factors for ulnar tunnel syndrome: a cadaveric study. Clin. Anat., 18(4):274-80, 2005.

Cihák, R. Ontogenesis of the skeleton and intrinsic muscles of the human hand and foot. Ergeb. Anat. Entwicklungsgesch., 46(1):5-194, 1972.

Depuydt, K. H.; Schuurman, A. H. \& Kon, M. Reversed palmaris longus muscle causing effort-related median nerve compression. J. Hand Surg. Br., 23(1):117-9, 1998. 
Harvie, P.; Patel, N. \& Ostlere, S. J. Prevalence and epidemiological variation of anomalous muscles at guyon's canal. J. Hand Surg. Br., 29(1):26-9, 2004.

Jones, D. P. Bilateral palmaris profundus in association with bifid median nerve as a cause of failed carpal tunnel release. J. Hand Surg. Am., 31(5):741-3, 2006.

Morrison, J. T. A palmaris longus muscle with a reversed belly, forming an accessory flexor muscle of the little finger. $J$. Anat. Physiol., 50(Pt. 4):324-6, 1916.

Natsis, K.; Levva, S.; Totlis, T.; Anastasopoulos, N. \& Paraskevas, G. Three-headed reversed palmaris longus muscle and its clinical significance. Ann. Anat., 189(1):97$101,2007$.

Ogun, T. C.; Karalezli, N. \& Ogun, C. O. The concomitant presence of two anomalous muscles in the forearm. Hand (N. Y.), 2(3):120-2, 2007.

Ruocco, M. J.; Walsh, J. J. \& Jackson, J. P. MR imaging of ulnar nerve entrapment secondary to an anomalous wrist muscle. Skeletal Radiol., 27(4):218-21, 1998.

Ryu, J. Y. \& Watson, H. K. SSMB syndrome. Symptomatic supernumerary muscle belly syndrome. Clin. Orthop. Relat. Res., (216):195-202, 1987.

Sánchez Lorenzo, J.; Cañada, M.; Díaz, L. \& Sarasúa, G. Compression of the median nerve by an anomalous palmaris longus tendon: a case report. J. Hand Surg. Am., 21(5):85860, 1996.

Santoro, T. D.; Matloub, H. S. \& Gosain, A. K. Ulnar nerve compression by an anomalous muscle following carpal tunnel release: a case report. J. Hand Surg. Am., 25(4):7404, 2000.

Sañudo, J. R.; Mirapeix, R. M. \& Ferreira, B. A rare anomaly of abductor digiti minimi. J. Anat., 182(Pt. 3):439-42, 1993.

Schuurman, A. H. \& van Gils, A. P. Reversed palmaris longus muscle on MRI: report of four cases. Eur. Radiol., 10(8):1242-4, 2000.

Server, F.; Miralles, R. C. \& Galcerá, D. C. Carpal tunnel syndrome caused by an anomalous palmaris profundus tendon. J. Anat., 187(Pt. 1):247-8, 1995.

Soldado-Carrera, F.; Vilar-Coromina, N. \& Rodríguez-Baeza, A. An accessory belly of the abductor digiti minimi muscle: a case report and embryologic aspects. Surg. Radiol. Anat. 22(1):51-4, 2000.

Yildiz, M.; Sener, M. \& Aynaci, O. Three-headed reversed palmaris longus muscle: a case report and review of the literature. Surg. Radiol. Anat., 22(3-4):217-9, 2000.
Zeiss, J. \& Guilliam-Haidet, L. MR demonstration of anomalous muscles about the volar aspect of the wrist and forearm. Clin. Imaging, 20(3):219-21, 1996.

Zeiss, J. \& Jakab, E. MR demonstration of an anomalous muscle in a patient with coexistent carpal and ulnar tunnel syndrome. Case report and literature summary. Clin. Imaging, 19(2):102$5,1995$.

\section{Correspondence to: Javier Román Veas Medico Traumatólogo \\ Profesor Asistente \\ Departamento de Ortopedia y Traumatología \\ Departamento de Anatomía \\ Pontificia Universidad Católica de Chile \\ Santiago \\ CHILE}

Email: romanjavi@gmail.com

Received: 17-05-2015

Accepted: 10-10-2015 